PONTIFíCIA UNIVERSIDADE CATÓLICA DO RIO DE JANEIRO

\title{
A Educação Financeira nas Escolas \\ O Impacto desta Educação na Inserção do Aluno na Universidade
}

Daniel Griner Villela

tRabalho de Conclusão de CuRso

Centro de ciências socials - CCS

Departamento de AdMinistraÇÃo

Graduação em Administração de Empresas 
Daniel Griner Villela

\author{
A Educação Financeira nas Escolas \\ O Impacto desta Educação na Inserção do Aluno na Universidade \\ Trabalho de Conclusão de Curso \\ Trabalho de Conclusão de Curso, apresentado ao \\ programa de graduação em Administração da PUC-Rio \\ como requisito parcial para a obtenção do título de \\ graduação em Administração.
}

Orientador: Liana Ribeiro dos Santos, PhD

Rio de Janeiro

Junho de 2019. 


\section{Agradecimentos}

Primeiramente, agradeço aos meus familiares pelas oportunidades de estudo, pela compreensão e pela ajuda em todos estes anos em que estive na faculdade. Agradeço principalmente à minha mãe, que fez tudo isso ser possível através de seu esforço ao longo desses anos.

Aos meus amigos e colegas que fiz durante a faculdade, que tornaram estes anos mais leves e me ajudaram com as dificuldades durante o curso. Foram muitas alegrias e amizades que espero levar para o resto da vida.

Agradeço também a minha orientadora Liana Ribeiro pelo apoio e instrução dados nesse semestre, com análises e comentários que auxiliaram na construção deste trabalho. 


\section{Resumo}

Griner Villela, Daniel. A Educação Financeira nas Escolas. Rio de Janeiro, 2019. Número de páginas $54 p$. Trabalho de Conclusão de Curso Departamento de Administração. Pontifícia Universidade Católica do Rio de Janeiro.

Este trabalho tem o intuito de mostrar o quanto a educação financeira é importante na vida de um indivíduo. O objetivo final do trabalho é exaltar a importância de se ter este contato desde cedo, evidenciando que a presença de matérias sobre finanças pessoais nas escolas é crucial para o aluno desenvolvolver uma boa gestão financeira pessoal. A metodologia utilizada foi uma pesquisa exploratória de categoria quantitativa, no qual tinha como público alvo o público universitário e pessoas recém-formadas e esta pesquisa ocorreu no primeiro semestre de 2019. Os resultados indicaram que a maioria dos entrevistados também acreditam que não obtiveram uma educação financeira formal em suas escolas. Além disso, é visto que as iniciativas que já estão em prática hoje em dia estão surtindo um efeito positivo e devem continuar para a melhoria da educação financeira no país.

Palavras-chave

Educação financeira, escolas, alunos, universidade, gestão financeira, risco financeiro, produtos financeiros de investimento, dívidas. 


\section{Abstract}

Griner Villela, Daniel. Financial Education in Schools. Rio de Janeiro, 2019. Número de páginas 54p. Trabalho de Conclusão de Curso - Departamento de Administração. Pontifícia Universidade Católica do Rio de Janeiro.

This article intends to show how important it is to have a financial education in a person's life. The final objective in this work is to exalt the importance of having this contact since early, showing that the presence of lessons about personal finances in schools is crucial for the student to develop a good personal financial management. In the methodology, it was applied an exploratory research of quantitative category in which had the university public in the target audience and the ones who just graduated and this research happened in the first semester of 2019. The results showed that the majority of the interviewed also believe that they didn't receive a formal financial education in their schools. Besides that, it's seen that these initiatives that are already in action are having a positive effect and they must continue to increase the financial education in the country.

Key-words

Financial education, schools, student, university, financial management, financial risk, investment financial products, debts. 


\section{Símbolos, Abreviaturas, Siglas e Convenções}

AEF - Associação de Educação Financeira do Brasil

API - Análise de Perfil do Investidor

B3 - Brasil, Bolsa, Balcão

BACEN - Banco Central

BM\&F - Bolsa de Mercadorias e Futuros

BNCC - Base Nacional Comum Curricular

BNDES - Banco Nacional de Desenvolvimento Econômico e Social

BOVESPA - Bolsa de Valores de São Paulo

CDB - Certificado de Depósito Bancário

CDI - Certificado de Depósito Interbancário

CEF - Caixa Econômica Federal

COE - Certificado de Operações Estruturadas

CONEF - Conselho Federal de Educação Financeira

CONSED - Conselho Nacional de Secretários de Educação

CVM - Comissão de Valores Mobiliários

DSOP - Diagnosticar, Sonhar, Orçar e Poupar

ENEF - Estratégia Nacional de Educação Financeira

IBGE - Instituto Brasileiro de Geografia e Estatística

IPCA - Índice de Preços ao Consumidor Amplo

LCI - Letras de Crédito Imobiliário

LCA - Letras de Crédito do Agronegócio

PIB - Produto Interno Bruto

PGBL - Plano Gerador de Benefício Livre

MEC - Ministério da Educação e Cultura

OCDE - Organização para Cooperação e Desenvolvimento Econômico

SUSEP - Superintendência de Seguros Privados

UNDIME - União Nacional dos Dirigentes Municipais de Educação 


\section{Sumário}

1. Introdução 1

1.1. O tema e o problema de estudo 1

1.2. Objetivo do estudo 3

1.3. Objetivos intermediários do estudo 4

1.4. Delimitação e foco do estudo 5

1.5. Justificativa e relevância do estudo 5

2. Referencial Teórico 8

2.1. Educação Financeira nas Escolas 8

2.2. Gestão financeira pessoal de investimentos 10

2.3. Risco em investimentos financeiros 12

$\begin{array}{ll}\text { 2.4. Produtos financeiros de investimento } & 14\end{array}$

3. Métodos e procedimentos de coleta e de análise de dados 18

3.1. Etapas de coleta de dados 18

3.2. Procedimentos e instrumentos de coleta de dados utilizados no estudo 19

3.3. Formas de tratamento e análise dos dados coletados para o estudo 20

3.4. Limitações do estudo

4. Apresentação e análise dos resultados 22

4.1. Etapa única: Aplicação do Questionário 22

4.1.1. Descrição do perfil dos respondentes 22

4.1.2. Descrição e análise dos resultados do público alvo 23

4.1.3. Análise do público presente no mercado financeiro 25 
5. Conclusões

6. Referências Bibliográficas

Documentos Anexos 


\section{Lista de Figuras}

Figura 1 - Dimensões espacial e temporal da educação financeira 


\section{Lista de Gráficos}

Gráfico 1 - Evolução do PIB no Brasil 1

Gráfico 2 - Carteira de abril 2019 Santander perfil moderado 5

Gráfico 3 - Carteira de abril 2019 Santander perfil arrojado 23

Gráfico 4 - Importância da educação financeira nas escolas 24

Gráfico 5 - Ivestimentos financeiros dos respondentes 25

Gráfico 6 - Por que você não investe hoje? 26 


\section{Lista de Quadros}

Quadro 1 - Perfil dos respondentes 


\section{Introdução}

O intuito deste capítulo é apresentar o tema a ser desenvolvido e o seu problema de estudo. Assim, apresenta-se o problema que suscitou a proposta de investigação e respectivos objetivos de pesquisa. Na sequência, são indicadas as suposições e as hipóteses do estudo e se informa a relevância e justificativa do estudo e a delimitação e foco do estudo.

\subsection{O tema e o problema de estudo}

Como é ressaltado por Savóia et al. (2007) e Bruhn et al. (2013), no Brasil as pessoas ainda carecem de uma educação financeira e estão dentro de um contexto em que o país vem passando por mudanças estruturais em sua economia. Assim, desde a década de 1990, os cidadãos se veem impelidos a rever suas formas de lidar com suas finanças pessoais, segundo Von Rooij (2011 apud DONADIO, 2016). A última mudança significativa na economia brasileira foi na época de 1994, quando foi introduzido o plano real, dando início a uma estabilização econômica do país (UOL, 2014). Após a implementação deste plano, ao comparar as outras moedas em outras décadas, a realidade vivida anteriormente era de uma hiperinflação.

Tal mudança auxiliou na economia dos brasileiros, pois como destaca-se no gráfico abaixo, é possível observar a evolução do PIB per capita brasileiro entre 1948 (ano em que o IBGE começou o cálculo do produto brasileiro) e 2012 em mil dólares americanos:

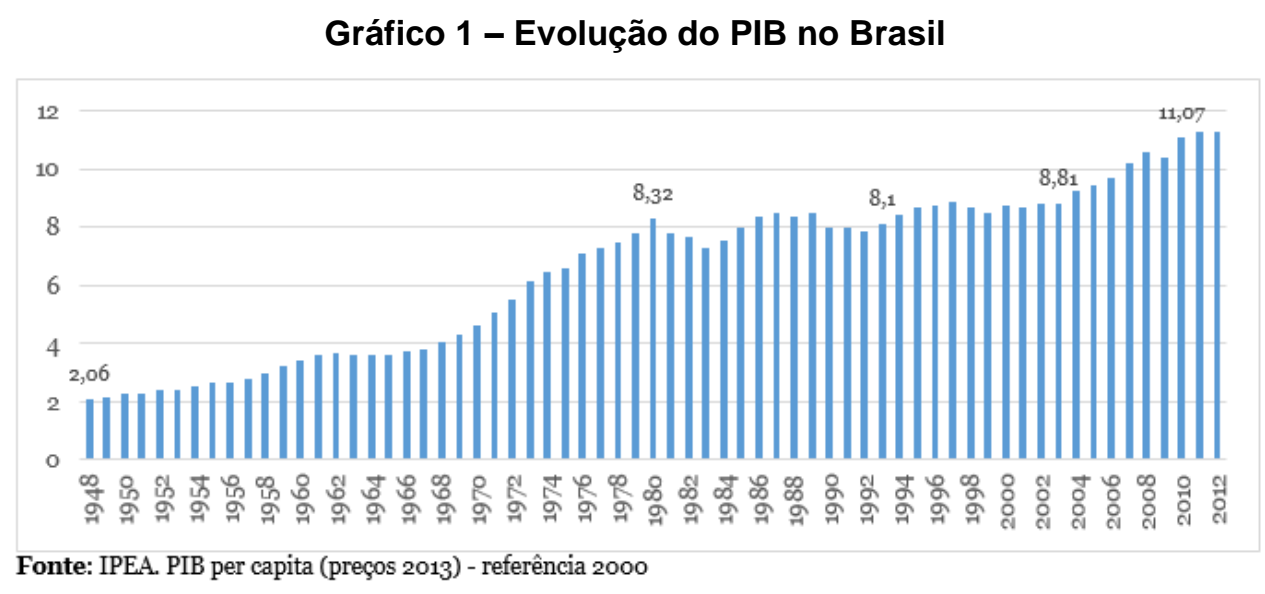


Segundo Andrada (2016), durante esse período acreditava-se que os problemas do Brasil eram dois: dívida pública (interna e externa) e a inflação. Resolvidos esses problemas, o país voltaria a crescer. Além disso, ele destaca também que, em 1994, após a implementação do Plano Real e durante os anos de Fernando Henrique Cardoso, a questão da inflação foi resolvida, pois o Índice de Preços ao Consumidor Amplo (IPCA) que fora de incríveis 2.477,15\% em 1993, passou para 22,41\% em 1995, ficando abaixo de um dígito em 1996.

Assim, a relação que pode ser estabelecida, era a de que enquanto o país não apresentasse uma economia estável, era difícil convencer pessoas a entrarem em qualquer tipo de investimento referente ao mercado financeiro. Um fato importante é de que o investidor não vai buscar o mercado, caso ele não possua o conhecimento necessário, como é destacado por André Bona (2018), em seu blog (BTG Pactual):

\footnotetext{
"a confiança é não apenas importante, mas essencial para o investidor, evitando que ele desista de realizar seus aportes ou construir sua carteira de investimentos na primeira dificuldade que aparecer pelo caminho." Além disso, ele destaca também que: "esta mesma confiança tende a aumentar, dia após dia, conforme o conhecimento do investidor vai se expandindo e se solidificando" (BONA, 2018).
}

A partir de uma pesquisa feita pelo Instituto Rosenfield (2012 apud CALEGARI, 2012), $43,5 \%$ dos entrevistados dizem não ter conhecimento sobre o mercado de ações e por isso não investem. Com isso, analisou-se que Gilligan (2012 apud CAMOZZATO et al., 2017) acredita que a falta de educação financeira pode trazer consequências no longo prazo. Através disso, é importante destacar que o básico da educação financeira tem que ser passado aos estudantes antes mesmo de ingressarem nas faculdades. É importante destacar o incentivo neste tipo de educação desde a escola, pois é algo essencial para o aprendizado e para ajudar nos controles das despesas desde cedo.

A relevância deste estudo é essencial pois visa a melhora na vida de grande parte da população, visando que o assunto abordado é pouco conhecido ainda no Brasil. Já visando a iniciativa feita pela ENEF (Estratégia Nacional de Educação Financeira), no qual tem-se o intuito de mostrar que a educação financeira tem um papel fundamental ao desenvolver competências que permitem consumir, poupar e investir de forma responsável e consciente, propiciando uma base mais segura para o desenvolvimento do país. Tal desenvolvimento retorna para as pessoas sob a forma de serviços mais eficientes e eficazes por parte do Estado, numa relação saudável das partes como o todo.

Na entrevista de Thiago Guedes (2017 apud DINO, 2017) para a exame, é ressaltado que um pensamento comum dos brasileiros é o de que investimentos de pouco valor não valem a pena, pois rendem pouco e podem ser compensados com aplicações maiores no futuro. 
Todavia, uma ideia que comprova o fato de que investir desde cedo é essencial, é a dos juros compostos, os juros sobre juros. Por exemplo, se em um mês você depositar $\mathrm{R} \$ 500,00$ em uma aplicação que rende $1 \%$ ao mês, no mês seguinte, os juros incidirão sobre o valor $\mathrm{R} \$ 505$. Ou seja, o consultor explica também que quanto antes você começar, menos dinheiro irá aportar para conseguir seus objetivos.

Após falar sobre a relação que a pessoa constrói com o dinheiro, observa-se o foco da pesquisa: o problema do assunto é que a palavra "investir" ainda não faz parte do dicionário de muitos universitários. Isso ocorre por alguns motivos que serão analisados durante a pesquisa, são eles: a falta de conhecimento sobre educação financeira; falta de uma maior busca de informações sobre o tema; o medo que alguns tem de investir (fatores emocionais); não conseguir separar o dinheiro para investimentos; renda muito baixa.

Porém, isto está mudando, conforme a informação a seguir: A bolsa de valores brasileira ganhou mais de 55 mil novos investidores no ano passado. $O$ aumento mais significativo, no entanto, foi entre os jovens de 16 a 25 anos, cuja participação cresceu 28,6\%. Em um ano, eles saíram de pouco mais de 14 mil aplicadores - o que representava, no fim de 2016, 2,5\% do total - para 18,4 mil, 3\% do todo registrado ao fim de 2017, segundo dados da própria B3 (LARGHI, 2018).

Por fim, será apresentado no trabalho diversos tipos de investimento em que o público estudado pode aderir, como fazer investimentos de pouco risco, em renda fixa e fundos de investimento e, também, caso o indivíduo já possua um conhecimento maior, o mercado de ações é outro exemplo, porém, com um risco mais elevado. Além disso, será mostrado como o jovem poderá acessar estes investimentos, por exemplo, através de corretoras e distribuidoras de valores de forma online e prática.

Dentro desse contexto, a presente pesquisa apresenta um questionamento que será debatido ao longo dela: Será que a educação financeira recebida pelos jovens nas escolas, antes de ingressar nas universidades, é suficiente para auxiliá-los quando entram no mercado de trabalho e querem poupar dinheiro para realizar investimentos financeiros?

\subsection{Objetivo do estudo}

Este trabalho tem como objetivo final analisar a importância e impacto do contato desde cedo, nas escolas, que a educação financeira tem sobre o indivíduo. Outros motivos que levam os jovens a não estarem investindo também serão levados em conta, como uma falta de orientação, falta na educação financeira, não conseguir separar o dinheiro, pois o gasta em bens que não são necessários para ele, entre outros. A partir da análise feita a respeito 
do público alvo da pesquisa, o intuito é mostrar ao universitário a necessidade de ele possuir bons hábitos que uma boa educação financeira ensina, como poupar, economizar e saber separar o dinheiro. Além disso, a pesquisa também buscará refletir o conhecimento dos jovens de hoje sobre os produtos que são oferecidos dentro do mercado financeiro. Por fim, irá ser explorado também quando foi feito o primeiro contato do jovem com este tipo de educação, se as escolas estão se mobilizando para a inserção de matérias relacionadas a isto em sua grade acadêmica.

Pretende-se, portanto, entender como a existência de matérias nas escolas impactam o jovem a melhorar sua educação financeira e também visa entender como ela pode influenciar na vida das pessoas (investimentos bem feitos, gastos com bens supérfluos, geração de dívidas, entre outros).

\subsection{Objetivos intermediários do estudo}

Para se atingir o objetivo final proposto esse estudo prevê, como objetivos intermediários a serem alcançados:

- Identificar o perfil do jovem, junto ao seu perfil financeiro, ver se ele teve uma educação financeira formal, conhecendo os hábitos de poupar, controlar e separar.

- Identificar o grau de conhecimento dos universitários a respeito de Educação Financeira.

- Entender se os jovens conhecem os produtos que o mercado financeiro de investimentos oferece, como títulos de tesouro direto, CDBs, fundos de investimento e ações.

- Busca-se, por fim, entender o comportamento do jovem e o que o leva a investir e não investir, avaliando o comportamento das despesas deles. 


\subsection{Delimitação e foco do estudo}

Este estudo volta-se mais especificamente para abordar como está sendo feita a gestão financeira pessoal de investimentos dos jovens que estão no mercado de trabalho. A aplicação da pesquisa de campo ocorrerá no 1ํ semestre de 2019.

A análise a ser feita busca provar ao indivíduo que ele está deixando de lado algo que está em um crescimento muito grande e mostrá-lo que é possível destinar uma renda para investimentos e que se pode juntar uma boa renda em um longo prazo. O trabalho também busca compreender o comportamento do universitário quanto às ações que são ou não tomadas nos investimentos e trazer dados que comprovam que o sistema e população brasileiro ainda carece quanto a este assunto.

O foco também está em mostrar ao público alvo da pesquisa que existem investimentos seguros e adequados aos perfis encontrados na pesquisa, que oferecem baixos riscos. $O$ estudo vai buscar mostrar os tipos de investimentos que podem ser feitos, os diferentes tipos de títulos privados, títulos públicos, investimentos em fundos e até um certo foco em renda variável, o que necessita de um entendimento maior sobre o mercado.

\subsection{Justificativa e relevância do estudo}

Portanto, a pesquisa pode vir a influenciar os universitários de modo que não se sintam mais inseguros ao começar algum investimento. O estudo também é relevante para incentivar ainda mais a cultura da educação financeira no Brasil. Além disso, a educação financeira irá afetar também as empresas, pois quando o funcionário tem uma vida financeira saudável, é normal que ele trabalhe com mais motivação e seja mais produtivo, com um motivo a menos para se preocupar. Como exemplos negativos de uma falta de prática das finanças pessoais na carreira, as pessoas muitas vezes não sabem onde e como devem fazer para o controle dos gastos e, muitas vezes, acabam contratando serviços que são prejudiciais para estes assuntos, como o de cheque especial, cartão de crédito, que ambos contam com a presença de juros. Tal assunto também é de extrema relevância para as escolas, pois como já citado no trabalho, quanto mais cedo houver o contato do indivíduo com esta educação, mais cedo o hábito de poupar vai fazer parte da vida das pessoas.

Com isso, o estudo feito busca incentivar os jovens universitários a entrar no mundo dos investimentos, pois o quanto mais cedo ingressam nesse mundo, mais fácil será de acumular um montante significativo após alguns anos de estar formado na faculdade. Um dos focos da pesquisa será mostrar a relevância do assunto para o público alvo dela. Como já foi dito 
anteriormente, quanto mais cedo for feito o ingresso neste meio, os sonhos que muitos jovens têm poderão ser alcançados caso já tenham tido o contato com esta educação desde cedo. Busca-se também mostrar os números atuais sobre a educação financeira no país, por isso, ao longo do trabalho, irá transparecer o quanto o sistema brasileiro ainda é precário quanto a este tipo de ensino.

Assim, para conclusão deste tópico, entende-se que a educação financeira, segundo a visão do programa, é inteiramente comprometida com o estar no mundo (AEF, 2017). Desta forma, em relação ao modelo de educação financeira adotado atualmente, acredita-se que o cotidiano acontece sempre em um espaço e tempo determinados. Ainda segundo a Associação de Educação Financeira (AEF),

\begin{abstract}
"na dimensão espacial, os conceitos da educação financeira se pautam no impacto das ações individuais sobre o contexto social, ou seja, das partes com o todo e vice-versa. Essa dimensão compreende ainda os níveis individual, local, regional, nacional e global, que se encontram organizados de modo inclusivo. Já na dimensão temporal, os conceitos são abordados com base na noção de que as decisões tomadas no presente podem afetar o futuro. Os espaços são atravessados por essa dimensão que conecta passado, presente e futuro numa cadeia de inter-relacionamentos como mostra a ilustração [abaixo]" (AEF-Brasil, 2017)
\end{abstract}

Figura 1 - Dimensões espacial e temporal da educação financeira

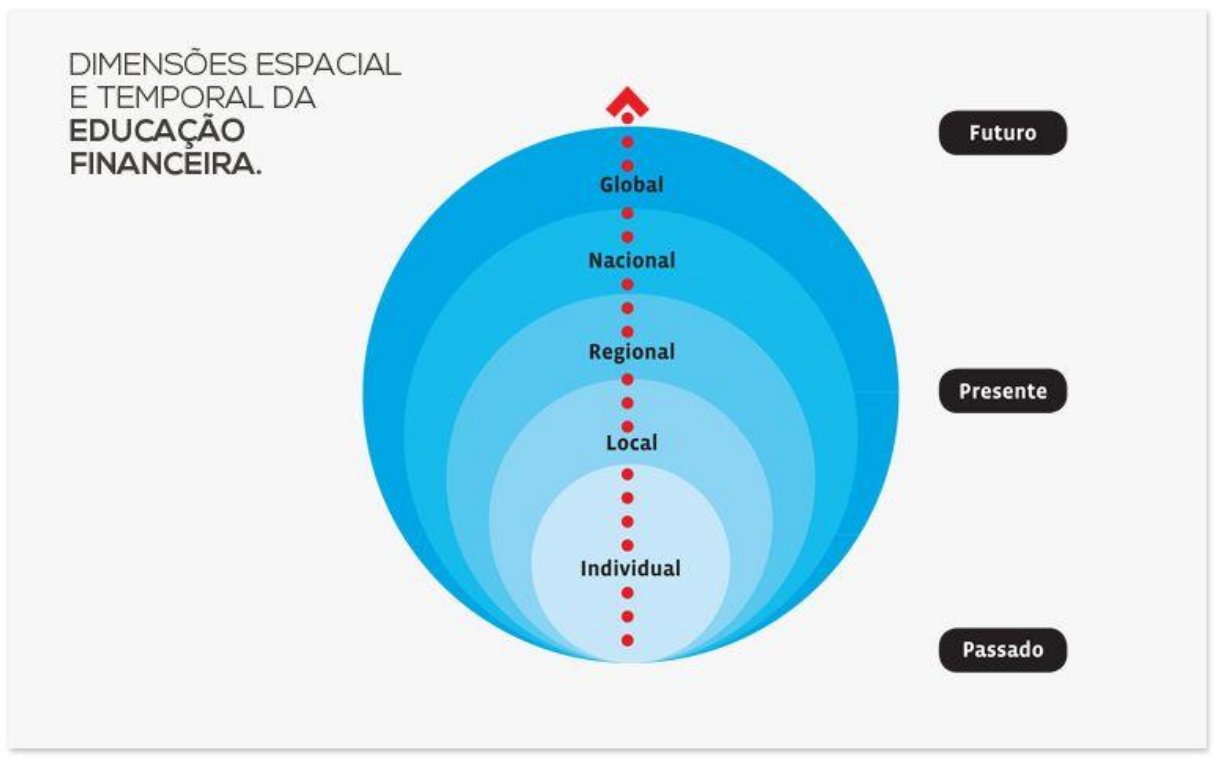

Fonte: AEF-Brasil (2017)

Por fim, serão abordadas as iniciativas que estão sendo feitas já nos dias de hoje, muitas delas, por parte da Associação de Educação Financeira no Brasil (AEF - Brasil). Em destaque no seu site, há o programa de educação financeira nas escolas, que é dividido em dois 
projetos, sendo um no ensino fundamental e outro no ensino médio, que contam com um projeto pedagógico e um conjunto de livros por níveis de ensino, que oferecem ao aluno e ao professor atividades educativas que permitem a inserção do tema na vida escolar. Além disso, é exibido também o documento "Orientação para Educação Financeira nas Escolas", que foi construído com a participação do Ministério da Educação (MEC), da União Nacional dos Dirigentes Municipais de Educação (UNDIME), Conselho Nacional de Secretários de Educação (CONSED) e outras instituições educacionais e financeiras ao longo de um ano, coordenado pela Comissão de Valores Mobiliários (CVM). A proposta principal é oferecer informações e orientações sobre a construção de um pensamento financeiro consistente e o desenvolvimento de comportamentos autônomos e saudáveis (AEF-Brasil, 2017). 


\title{
2. Referencial Teórico
}

\subsection{Educação Financeira nas Escolas}

Segundo a Organização para Cooperação e Desenvolvimento Econômico, educação financeira é definida como:

\begin{abstract}
"o processo mediante o qual os indivíduos e as sociedades melhoram sua compreensão dos conceitos e produtos financeiros, de maneira que, com informação, formação e orientação claras, as pessoas adquirem os valores e as competências necessários para se tornarem mais conscientes das oportunidades e dos riscos neles envolvidos e, então, poderem fazer escolhas bem informadas, saber onde procurar ajuda e adotar outras ações que melhorem o seu bem-estar. Assim, podem contribuir de modo mais consistente para a formação de indivíduos e sociedades responsáveis, comprometidos com o futuro" (OCDE, 2005 apud PREVIC, [200-?]).
\end{abstract}

O mercado financeiro, embora não esteja sendo ainda muito explorado por jovens investidores, tem mostrado grande potencial de crescimento nos últimos anos. Assim, será evidenciado que para conseguir alcançar sonhos e objetivos, é essencial para o indivíduo possuir uma base de conhecimento para conseguir controlar suas despesas e destinar seu dinheiro para investimentos.

Ao serem feitos estudos sobre o tema, aprender sobre educação financeira dentro da sala de aula é fundamental para o fortalecimento da cidadania. Pois ao estar ambientado com o assunto, o aluno se torna mais consciente sobre a importância de tomar decisões acertadas sobre finanças e consumo. Para Sandra Tiné (2017 apud MEC, 2017), que é presidente do grupo de apoio pedagógico do Comitê Nacional de Educação Financeira (Conef) e também é assessora técnica da Secretaria de Educação Básica do MEC, ela chama atenção sobre o que é o verdadeiro significado de ser financeiramente educado: "Isso são coisas que devem ser trabalhadas desde o início da escolarização, com as crianças", explica. "Se olharmos as últimas pesquisas, vemos que ainda somos um país de pessoas superendividadas e isso compromete o desenvolvimento do país. Queremos e precisamos ser um país de poupadores" (TINÉ, 2017 apud MEC, 2017). Para completar o raciocínio, ela fala também que: "Uma criança que aprende a poupar, que fecha a torneira e que tem essas preocupações com a sustentabilidade, leva tudo isso para casa. Isso se reflete nas famílias, é uma ação que parte da escola para toda a sociedade" (TINÉ, 2017 apud MEC, 2017). Esse conhecimento é importante pois não é só o futuro dos jovens que está em foco, mas o do país também. 
Uma nova metodologia está começando a ser aplicada em algumas escolas, tal forma foi desenvolvida por Reinaldo Domingos (2008), em que está sendo proposta uma nova metodologia, a DSOP - Diagnosticar, sonhar, orçar e poupar. Este método "oferece uma série de produtos e serviços sob medida para pessoas, empresas e instituições de ensino interessadas em ampliar e consolidar o conhecimento sobre o tema" (DOMINGOS, 2008, p. 105).

Por fim, para destacar as iniciativas feitas pela ENEF, é importante mostrar que algumas atitudes estão sendo tomadas quanto à busca para uma melhora no sistema de educação financeira do país. Como é exemplificado por Goldfajn (2018 apud BCB, 2018), em seu discurso na 5a Semana de Educação Financeira, há pilares que contribuem para a promoção da cidadania financeira de nossa população. É possível analisar os seguintes impactos destes pilares:

- Aumentar o nível de educação financeira da sociedade brasileira;

- Ampliar a inclusão financeira da população;

- Fortalecer o ambiente institucional para manutenção da estabilidade financeira, no interesse da sociedade;

- Diminuir o custo do crédito para o cidadão.

Ainda no pronunciamento do ex-presidente do Banco Central em seu discurso de abertura da $5^{\text {a }}$ semana de educação financeira, é destacado também por Goldfajn (2018) que:

"No campo da educação financeira, além da atuação do Banco Central, apresentada pelo Diretor Maurício, que representa o Banco Central no Conef, gostaria de ressaltar o esforço empreendido pelas diversas entidades aqui presentes para que o tema da educação financeira fizesse parte da Base Nacional Comum Curricular, a BNCC" (GOLDFAJN, 2018 apud BCB, 2018, p.3).

Para entender melhor, a Base Nacional Comum Curricular trata-se de um documento que busca selecionar e padronizar o que é considerado como aprendizagem essencial que virá a ser trabalhada nas escolas, públicas ou particulares, nos ensinos infantil, fundamental e médio, visando a aprendizagem e o desenvolvimento de todos os estudantes do brasil (INSTITUTO AYRTON SENNA, 2018). Para concluir, Goldfajn (2018 apud BCB, 2018) diz:

"a BNCC apresenta a educação financeira como tema a ser incorporado, preferencialmente de forma transversal e integradora, 
aos componentes curriculares na escola. São diversas as possibilidades de integração da educação financeira e da educação econômica às Áreas do Conhecimento constantes da Base Curricular" (GOLDFAJN, 2018 apud BCB, 2018, p.4).

Para ratificar as atitudes que estão sendo tomadas, no mês de maio ocorrerá a 6aㅗ Semana Nacional de Educação Financeira, entre os dias 20 e 26 de maio no Estado do Rio de Janeiro, como é destacado no site da CVM. Dentre as ações que ocorrem no evento, são realizadas mesas-redondas e palestras gratuitas sobre educação financeira, inclusive sobre a aplicação do tema no ensino fundamental, abordando experiências práticas, resultados alcançados e projetos futuros. Palestras como "Educação financeira na infância" e "Por que educação financeira no Ensino Fundamental" são oferecidas, além da exibição do Projeto Educação Financeira nas escolas do ensino fundamental e também uma mesa sobre práticas na educação financeira de jovens e crianças. Por fim, a Semana ENEF tem como objetivo "disseminar a educação financeira e previdenciária no país, além de contribuir para o fortalecimento da cidadania" (COMISSÃO DE VALORES MOBILIÁRIOS, 2019).

\subsection{Gestão financeira pessoal de investimentos}

Começando a análise com a famosa frase de Albert Einstein, "a força mais poderosa do universo [são] os juros compostos" (D’ANDRÉA, 2013), pode-se entender a relação entre falta de conhecimento financeiro e geração de dívidas.

No primeiro indicativo que demonstra o pouco grau de conhecimento financeiro foi feita uma pesquisa, em 2008, realizada pelo Instituto Data Popular em conjunto com a BM\&FBOVESPA, tendo como objetivo mensurar o grau de educação financeira da população brasileira. Os dados revelaram que em geral o nível de educação financeira da população era baixo, além disso, a pesquisa apontou detalhes específicos da sociedade brasileira, que merecem reflexão por parte de formuladores de políticas públicas e pelo próprio mercado. Com isso, foi evidenciado também algumas práticas comuns para os brasileiros: "69\% indicaram usar planilhas para acompanhar os gastos da família e 66\% revelaram guardar comprovantes de suas compras" (MARQUES, 2018, p. 40). Um fato observado foi que estas práticas que eram feitas, não refletiam efeitos prolongados sobre a saúde financeira da população, haja vista as pressões e urgência das necessidades diárias, que impediam uma melhor assimilação das informações por parte dos entrevistados (SOARES, 2016 apud MARQUES, 2018, p. 40).

"O segredo do sucesso não é tentar evitar os problemas nem se esquivar ou se livrar deles, mas crescer pessoalmente para se tornar maior do que qualquer adversidade" (EKER, 
2005, p. 74). O autor destaca que, para passar para a próxima fase do sucesso, é importante para o indivíduo se conscientizar do que de fato acontece na sua vida. Um dos pontos a serem estudados, dirá respeito ao comportamento que leva muitos a deixarem de ganhar o que poderiam. Este comportamento é apresentado por Eker (2005), quando dito em um dos considerados princípios da riqueza: "Ou você controla o seu dinheiro ou ele o controlará" (EKER, 2005, p. 105). Ele afirma que: "o dinheiro é uma parte fundamental da existência humana. Quando você aprender a colocar as suas finanças sob controle, todos os setores da sua vida andarão bem" (EKER, 2005, p. 106). Por isso, observa-se um outro problema que, caso isso não ande em conjunto e existam pessoas em que não consigam deixar de gastar com bens não necessários e direcionar o dinheiro para investimentos, elas sempre serão pobres, não conseguindo avançar a longo prazo e ter uma vida financeira saudável.

Um dos princípios que é preciso se ter, para tentar começar a mudar a filosofia do dinheiro, é chamado Processo de Manifestação e tem a seguinte sequência: $P->S->A=R$. Nela, é explicado que os pensamentos conduzem a sentimentos. Sentimentos conduzem a ações. Ações conduzem a resultados (EKER, 2005). Ou seja, enquanto as pessoas não agirem e tentarem entender melhor sobre o assunto, não trará resultados e elas ficarão estagnadas.

"Estou muito preocupado pelo fato de que gente demais se preocupa excessivamente com dinheiro e não com a sua maior riqueza, a educação" (KIYOSAKI e LECHTER, 1997, p. 52). Ao longo do livro, Kiyosaki e Lechter (1997) mostram que as pessoas ainda não sabem direcionar da forma correta seu dinheiro, tem pensamentos de que não é possível se poupar dinheiro e não sabem diferenças às vezes entre produtos passivos e ativos. $E$, para poder concluir este tópico, em relação ao salário ganho, ele destaca que "a maioria das pessoas não percebe que na vida o que importa não é quanto dinheiro você ganha, mas quanto dinheiro você conserva" (KIYOSAKI e LECHTER, 1997, p. 52).

Um dos principais fatores a se considerar é o comportamento do jovem universitário, pois, como Stanley e Danko (1996) definem, riqueza é diferente da maioria dos dicionários: "Muitas pessoas que parecem ser ricas, por seu nível de consumo, estilo de vida e rendimentos altos, não têm reserva financeira nenhuma - e, portanto, não podem ser realmente consideradas ricas" (STANLEY e DANKO, 1996, p. 5). Como é de principal destaque dos autores, o verdadeiro milionário não ostenta, não gastam fortunas, não viajam como milionários porque para eles, estes são os verdadeiros ricos (STANLEY e DANKO, 1996).

Para ratificar o argumento de que as pessoas ainda não possuem o hábito de primeiro pensar em poupar, destaca-se a frase:

"O dinheiro oferece ao seu detentor, pelo menos em princípio, um puro instrumento através do qual se torna possível uma variedade quase ilimitada de oportunidades de uso. Assim sendo, afirmar que o dinheiro, como certo tipo de ferramenta, possui possibilidades 
ilimitadas de uso, em princípio é não dizer nada" (DODD, 1997, p. 107).

Nos dias de hoje, o dinheiro se tornou um dos bens mais importantes, não é mais considerado apenas uma moeda de troca ou apenas um papel, pois seu poder de compra carrega diversos significados, dentre eles alguns em aspectos sociais. Para o perfil dos jovens, o dinheiro é necessário para sobreviver, traz motivação e ainda oferece qualidade de vida às pessoas. Vale destacar um dos motivos para esta crença, no qual "O dinheiro, sempre e onde quer que seja usado, não se define por suas propriedades como objeto material, mas pelas qualidades simbólicas genericamente vinculadas ao ideal de concessão irrestrita de poder" (DODD, 1997, p. 235).

Baseado em alguns destes pensamentos, leva-se a pensar que ainda há barreiras que fazem a pessoa se perguntar se irá gastar o dinheiro com um bem que não é necessário no momento da compra desse bem. Com isso, pode-se concluir que para o jovem, ainda é necessária uma mudança de pensamento e prioridades.

Neste sentido, Kiyosaki (1997) argumenta que para a sua vida pessoal, é preciso aprender autodisciplina, que é o mais difícil de se dominar. Além disso, quanto aos investimentos, é preciso entender um pouco mais, aprendendo o sentido econômico de um investimento, sabendo gerir o seu risco. Por fim, na vida profissional, ele destaca também que a procura de um emprego é pela oportunidade de aprender mais do que pelo dinheiro em si, pois ele é apenas consequência.

\subsection{Risco em investimentos financeiros}

Atualmente, é de suma importância entender a definição de risco nos investimentos, que é definida pelo Dicionário Financeiro como: "Risco é o grau de incerteza em relação à rentabilidade de um investimento. Isso significa a chance de o investimento dar um retorno abaixo do esperado, de se perder tudo o que foi investido ou, em casos extremos, de a perda ultrapassar o valor do investimento original" (DICIONÁRIO FINANCEIRO, 2017).

Entre os riscos que podem afetar uma aplicação financeira, estão o risco de crédito, o risco de liquidez e o risco de mercado (BONA, 2018). Assim, o mercado oferece para o investidor diversos tipos de investimentos e, cada tipo de investimento, é recomendado para cada tipo de perfil de investidor. Para entender melhor, foi analisada a definição de perfil do investidor, como destacado por Bona no blog de Renda Fixa: "O perfil do investidor é identificado por meio destas preferências e objetivos do investidor, e permite uma distribuição 
dos investimentos mais compatível com o perfil de cada um. Em regra, existem três tipos de perfis: conservador, moderado e agressivo" (BONA, 2017).

Para o indivíduo saber em qual perfil se adequa, é feito um questionário, chamado API (Avaliação de Perfil do Investidor) ou Suitability, que ainda segundo o blog, ele faz uma série de avaliações que envolvem a renda e patrimônio do investidor, sua idade, projetos e objetivos futuros, nível de conhecimento do mercado, o prazo desejado para investimento, nível de tolerância ao risco, entre outros.

A partir disso, as corretoras e distribuidoras buscam entender o perfil do cliente e identificar qual é o perfil de risco do investidor e, assim, saberão o que recomendar para os seus clientes, de acordo com cada perfil. Quando o perfil é identificado como conservador, sabe-se que o indivíduo irá priorizar a preservação de seu capital, pois ele não estará disposto a correr riscos que comprometam o seu patrimônio e aceita uma menor rentabilidade, porém com maior segurança. O segundo tipo de perfil, o moderado, é aquele que: "está disposto a assumir certos riscos em busca de uma rentabilidade superior, sem abrir mão da segurança da carteira como um todo" (BONA, 2017). Ou seja, ele está disposto a alavancar um pouco os seus investimentos com alguns tipos de investimentos de maior risco, porém a sua carteira é composta na maioria de investimentos mais seguros. Por fim, analisou-se o perfil agressivo, que é aquele que tem investimentos de maior risco e é o investidor que busca uma maior rentabilidade num prazo de tempo menor. Ainda destacado no Blog: "Normalmente estes investidores têm um bom conhecimento do mercado e não se afligem com oscilações e volatilidades diárias ou possíveis instabilidades durante o investimento" (BONA, 2017).

Como pode ser observado, a recomendação em qual produto o cliente irá investir é oriunda do questionário do API. Tal prática de aplicar o questionário é primordial, segundo as instituições que regulam o mercado financeiro, sendo exibido na Instrução CVM 539 (2013): "Dispõe sobre o dever de verificação da adequação dos produtos, serviços e operações ao perfil do cliente". É importante que o perfil do cliente esteja sempre atualizado, considerar as operações realizadas pelo cliente, sua situação econômica, quais são seus objetivos de investimento, a sua tolerância ao risco e experiência. Outro ponto destacado na instrução, é que o lugar em que o indivíduo faça seus investimentos deve sempre oferecer produtos compatíveis com o perfil dele.

A B3 (2017) diz que:

"A regulamentação exige que o participante mantenha os dados cadastrais atualizados e que adote procedimentos de atualização após período de 24 meses. É importante entender que não se trata de refazer o cadastro do investidor, mas apenas certificar-se de que as informações fornecidas continuam válidas". 
Ao relacionar a aplicação do API com os tipos de investimento sugeridos, será feita uma análise e ver quais os produtos que são recomendados para os tipos de investidores existentes.

\subsection{Produtos financeiros de investimento}

A partir da análise feita sobre os perfis encontrados no mercado financeiro, como já mencionado anteriormente, cada tipo de investidor deve ser limitado a ter certos investimentos que são recomendados para o seu determinado tipo de perfil.

Também foi feito um levantamento pelo grupo de trabalho instituído pela Deliberação Coremec nำ3/2007, com o apoio da BM\&FBOVESPA quanto ao conhecimento da população sobre as instituições financeiras, como BACEN, BNDES, Bovespa, BM\&F, SUSEP, mas, em geral, as pessoas já ouviram falar sobre estas instituições. Além disso, a pesquisa mostra que "apenas $40 \%$ declararam que fazem algum investimento com o dinheiro que sobra, após pagarem suas despesas. Dessa amostra, a escolha de $78 \%$ é a conta de poupança" (ENEF, [2008], p.5). Com isso, fica visível a falta de conhecimento dos produtos oferecidos dentro do mercado financeiro e a escolha por investimentos que são seguros, porém, muito pouco rentáveis, como no caso da poupança.

Graham (1949), observa que: "Quanto mais o investidor depender de sua carteira de investimentos e da receita por ela gerada, mais necessário será que ele se proteja de qualquer acontecimento inesperado e desconcertante nessa etapa de sua vida" (GRAHAM,1949, p. 73). Com isso, o autor ainda diz que: "é incontestável que o investidor conservador deva buscar minimizar seus riscos" (GRAHAM,1949, p. 73). Com isso, para a Caixa Econômica Federal (2014), ele prioriza a segurança em seus investimentos, evita correr riscos que possam comprometer o seu patrimônio. Os investimentos apropriados para esse perfil são os classificados como risco muito baixo, baixo ou médio com pouca chance de perda. Assim, recomendam-se investimentos como Poupança, Renda Fixa (CDB - Certificado de Depósito Bancário, LCl e LCA - Letras de crédito imobiliário e do agronegócio), títulos públicos (tesouro direto) e fundos de renda fixa.

No caso do perfil moderado, este já aceita correr um pouco mais de risco em busca de uma melhor rentabilidade, e busca fazer isso direcionando a maior parcela de seus recursos para aplicações mais seguras (CEF 2014). Para a Genial Investimentos (2017), os investimentos moderados "podem, eventualmente, ter rendimentos negativos, dependendo das circunstâncias econômicas e do momento em que o investidor resolve resgatá-los ou vendê-los" (GENIAL INVESTIMENTOS, 2017). Em resumo para a corretora, os clientes que 
possuem estes investimentos buscam obter uma remuneração um pouco superior à taxa básica de juros para quem está disposto a correr riscos um pouco maiores. Uma das sugestões do Banco do Brasil (2014) é a de que os investidores arrojados buscam ter a possibilidade de maiores ganhos no longo prazo, para isso aceita correr mais riscos. Estes investimentos de um risco um pouco maior estão na renda variável nas ações, sendo importante diversificar os recursos. Com isso, pelo fato de acreditar que a alocação dos recursos financeiros para este tipo de perfil está coerente, analisou-se a carteira de investimentos sugerida para o perfil moderado do Banco Santander, válida para o mês de abril de 2019, vista no gráfico 2:

\section{Gráfico 2 - Carteira de abril 2019 Santander perfil moderado}

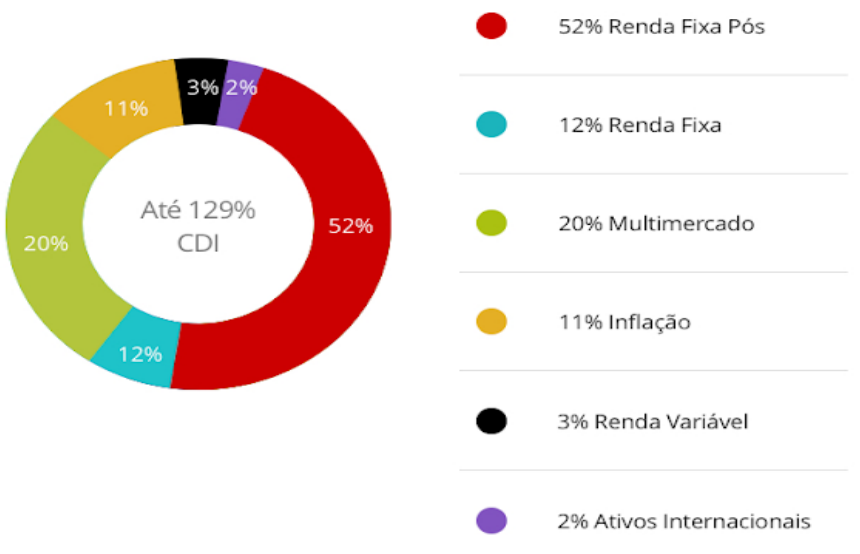

Fonte: Santander, 2019.

Nela, pode-se observar a porcentagem alocada para cada tipo de produto financeiro. Entende-se Renda fixa pós fixada por CDB DI, quando a aplicação é remunerada por um percentual fixo do CDI (Itaú, [201-]), Fundos DI, que possuem um portfólio 95\% comprado em títulos pós-fixados do Tesouro Nacional, oferecendo uma baixa volatilidade e rentabilidade próxima do índice de referência, o CDI (INFOMONEY, 2005) e LCl, título de renda fixa emitido por um banco e lastreado por empréstimos imobiliários. Os títulos podem ter rentabilidade pré ou pós-fixada. A composição de renda fixa é feita por previdência e tesouro pré-fixado. Já para o Multimercado, a composição é de COE (Certificado de Operações Estruturadas) Dólar, que "permite ao investidor escolher o cenário de acordo com a sua expectativa em relação ao mercado de juros, inflação, cambial ou acionário" (SANTANDER, 2019) e fundos multimercado, que "acessam diversos mercados ao mesmo tempo, como juros, câmbio e ações, além de investimentos no exterior" (SANTANDER, 2019). No caso da inflação, está dividido em debêntures incentivadas, que são Títulos de dívida emitidos por empresas que 
exercem atividades no ramo da infraestrutura, fundos atrelados à inflação e COE inflação. Já na parte de renda variável, há a presença de fundos de ações (que possuem mais de 67\% dos seus investimentos em ações), ações e fundos imobiliários, que possuem seus investimentos no mercado imobiliário com a possibilidade de maior liquidez e vantagens fiscais (Santander, 2019). A carteira que foi exibida no gráfico anterior, de abril deste ano, teve o desempenho de até $129 \%$ do CDI.

Por fim, para o Santander (2014), o perfil arrojado é aquele perfil que "é representado por clientes com alta tolerância a riscos, baixa ou nenhuma necessidade de liquidez no curto/médio prazo e que estejam dispostos a aceitar as oscilações dos mercados de risco (e possíveis perdas) na busca por retornos diferenciados no longo prazo". Além disso, como afirma o Banco do Brasil (2014), é necessário manter uma fatia de seus recursos em produtos de baixo risco, como forma de proteção do seu patrimônio. Para a XP Investimentos (2014), ela recomenda que produtos financeiros como fundos de renda fixa, ativos de renda fixa, fundos multimercado, fundos imobiliários, previdência privada e ações e BM\&F (Bolsa de Mercadorias e Futuros), que, como definido pela Toro Investimentos (2018) é responsável por possibilitar diversos tipos de investimentos. "Por meio dela, é possível negociar commodities agropecuárias, minerais, recursos naturais, moedas, taxas de juros e assim por diante". Lembrando que a alocação destes produtos irá variar, pois a porcentagem escolhida para cada um destes produtos financeiros é feita pelo do banco ou corretora.

A seguir, a comparação feita tem o intuito de evidenciar a diferença de alocação de produtos financeiros de uma carteira de investimentos do perfil moderado para o perfil arrojado. Pode ser observado no gráfico 3 a carteira de abril de 2019 recomendada pelo Santander, para o perfil arrojado:

\section{Gráfico 3 - Carteira de abril 2019 Santander perfil arrojado}

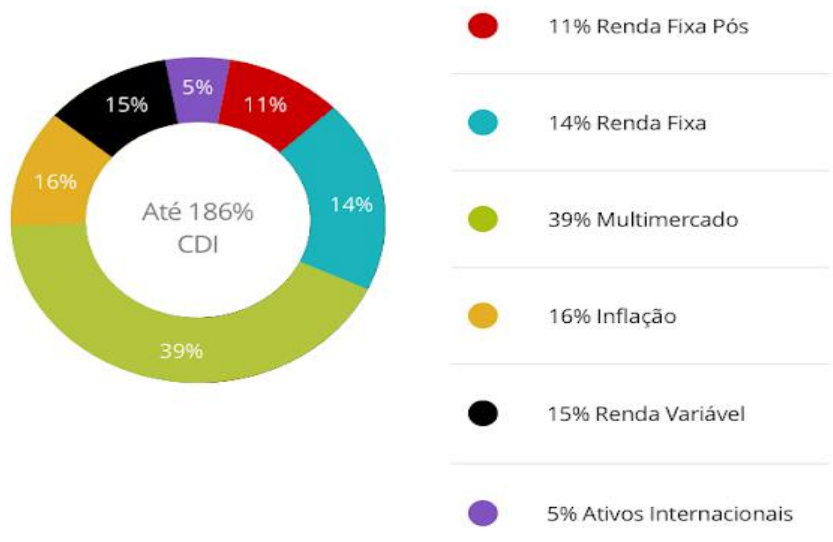

Fonte: Santander, 2019 
Assim, a proposta do capítulo é de sugerir uma alocação aproximada dos produtos financeiros para cada tipo de perfil do investidor e, como Eduardo Akira (apud D'ÁVILA, 2019) destaca, os mais arrojados possuem uma quantidade menor de renda fixa na carteira, mas mesmo assim possuem uma parcela para garantir liquidez. Os fundos de investimento, de multimercado, de ações e cambiais também são escolhas destes investidores. É de costume investir cerca de 22,5\% do portfólio em ações, conclui Akira. Ou seja, a porcentagem para cada tipo de produto varia para cada banco ou corretora que faz a recomendação ao seu cliente. 


\section{Métodos e procedimentos de coleta e de análise de dados}

Este capítulo tem o intuito de abordar a metodologia a ser utilizada como fonte de informações e recursos para o estudo. Desta forma, será explorada a pesquisa feita com o público alvo, ver os seus desdobramentos e buscar identificar os problemas encontrados e suas possíveis soluções, de acordo com a análise feita em cada ponto. A pesquisa feita com os alunos das universidades é exploratória de categoria quantitativa, pois como é definido por Mattar (2001), uma pesquisa para ser considerada quantitativa, ela deve buscar fazer a validação das hipóteses quando utilizados dados estruturados, estatísticos, e, com a análise de um grande número de casos representativos, sendo recomendado um curso final da ação a se tomar. Ela tem a responsabilidade de quantificar os dados e generalizar os resultados da amostra para quem possa interessar.

A fim de construir uma análise da pesquisa, um planejamento foi feito para isso. Abordado por Prodanov e Freitas (2013) em Metodologia do Trabalho Científico, "o planejamento de uma pesquisa dependerá basicamente de três fases:

A) Fase decisória: referente à escolha do tema, à definição e à delimitação do problema de pesquisa;

B) Fase construtiva: referente à construção de um plano de pesquisa e à execução da pesquisa propriamente dita;

C) Fase redacional: referente à análise dos dados e das informações obtidas na fase construtiva. É a organização das ideias de forma sistematizada visando à elaboração do relatório final“ (PRODANOV e FREITAS, 2013, p. 73).

O presente capítulo se encontra dividido em quatro seções, são elas: Etapa de coleta de dados, Procedimentos e instrumentos de coleta de dados utilizados no estudo, Formas de tratamento e Análise dos dados coletados para o estudo e Limitações do Estudo.

\subsection{Etapas de coleta de dados}

O público alvo da pesquisa referente à educação financeira nas escolas é o público universitário. Baseado nisso, busca-se coletar o maior número de informações e de pessoas sobre como foi introduzida a educação financeira na escola dela, caso tenha sido. A pesquisa 
foi realizada priorizando os jovens de 18 a 35 anos, com o enfoque principal em levantar dados para conseguir comprovar que hoje em dia o ensino desta educação nas escolas é ainda muito precário.

O estudo, que tem como base identificar as noções de finanças pessoais dos universitários de hoje em dia e se receberam na escola uma educação financeira formal ou não. Foi realizado com levantamento por meio de um questionário online, através do Qualtrics Survey Software. A utilização do questionário eletrônico apresenta algumas vantagens, como maior agilidade na aplicação, controle e acompanhamento das respostas; maior rapidez na tabulação dos resultados; flexibilidade e diversidade na formulação das questões (Evans e Mathur, 2005). A população foi formada por alunos de diversas instituições de ensino superior do Rio de Janeiro, como Pontifícia Universidade Católica (PUC - Rio), Universidade Federal Fluminense (UFF), Universidade Federal do Rio de Janeiro (UFRJ), Universidade do Estado do Rio de Janeiro (UERJ), Instituto Brasileiro de Mercado de Capitais (IBMEC) e Universidade Veiga de Almeida (UVA). De acordo com Hair (2005), recomenda-se que uma amostra não é suficiente ainda com apenas 50 observações e, é de preferência que o tamanho da amostra seja maior ou igual a 100 casos válidos, o que aconteceu na pesquisa (HAIR, 2005, p. 108). Por fim, o questionário passou por uma etapa de pré-teste, feito com uma base de 10 pessoas para verificar se estava coerente e de fácil entendimento. Com isso, o questionário contou com 16 questões ao todo, sendo delas 5 sobre perguntas gerais e 11 sobre assuntos de educação financeira.

\subsection{Procedimentos e instrumentos de coleta de dados utilizados no estudo}

A pesquisa de campo feita através do questionário tem como objetivo trazer os dados que o pesquisador está buscando. O questionário aplicado contou primeiro com a etapa de perguntas gerais, relacionadas à idade, gênero, a renda mensal de cada indivíduo, contando o tempo em que esteve ou está trabalhando mais outras formas de entrada de dinheiro, onde o jovem reside na cidade do Rio de Janeiro e se já é graduado ou se ainda está na faculdade.

A primeira pergunta sobre educação financeira do questionário, é a pergunta principal deste trabalho de curso, se o jovem de hoje considera ou não se teve uma educação financeira formal em sua escola e, a partir disso, houve a separação dos grupos, entre quem acredita que teve sim essa educação e como foi este contato e quem acredita que não a obteve. Para evidenciar que o estudo que está sendo feito é de relevância, perguntou-se o grau de importância que estes indivíduos dão para aulas de educação financeira no ensino fundamental e médio. Além disso, o público deve também responder se o contato com esta 
educação desde cedo, poderia vir a influenciar num melhor controle sobre suas finanças pessoais nos dias atuais e também, como foi feito o primeiro contato da pessoa com este tema. Além disso, há também uma pergunta sobre a prática de gestão financeira pessoal por parte do indivíduo. Os produtos financeiros de investimento também são abordados, se o público sabe diferenciá-los ou também se já investem em algum deles. A pesquisa também busca identificar o motivo de alguns não investirem, o seu tipo de investidor e como este investimento financeiro é feito.

Devido a aplicação da pesquisa ter sido feita por um questionário online, não há margem para respostas que diferem uma das outras. As perguntas de resposta única e múltipla escolha foram tratadas a partir de uma análise de frequência. Buscou-se identificar semelhanças e relações entre as respostas, para conseguir formar diferentes categorias.

\subsection{Formas de tratamento e análise dos dados coletados para o estudo}

A coleta de dados gerou 222 questionários respondidos, sendo todos considerados válidos. Os resultados obtidos através do questionário evidenciaram a diferença entre os dois grupos que foram separados, os que tiveram uma educação financeira nas escolas e os que não tiveram. Este questionário busca identificar a importância dos assuntos que estão presentes no referencial teórico, com perguntas diretas sobre este ensino nas escolas, que pela grande maioria não foi passado este conteúdo e a gestão financeira pessoal de investimentos de cada indivíduo.

$\mathrm{Na}$ análise de dados que foi obtida pelo relatório do Qualtrics, houve a presença de perguntas objetivas, com apenas uma opção para marcar, perguntas condicionais e contava com uma questão de mais de uma opção de escolha. $O$ intuito do questionário aplicado foi conseguir estabelecer uma ligação entre as respostas fornecidas do público da pesquisa e os pontos apresentados durante o trabalho. Além disso, buscou-se identificar as semelhanças de algumas respostas para formação de categorias diferentes dos respondentes. Com isso, a partir da análise dos resultados, foi possível estabelecer uma relação dos dados obtidos com o que foi apresentado no referencial teórico.

\subsection{Limitações do estudo}

Por se tratar de um questionário quantitativo e sem espaço para subjetividade, a etapa do processo de coleta de dados não apresentou problemas referente ao método e procedimento 
de coleta escolhido. Porém, serão identificadas a seguir algumas possibilidades de limitações metodológicas.

Inicialmente, tendo em vista que o questionário contava com 18 questões, pode ter havido alguma perda de informações para uma análise completa dos resultados da pesquisa aplicada com relação a todos os assuntos abordados neste trabalho. Pelo fato de não haver contato entre o pesquisador e os respondentes na aplicação do questionário, não há nenhum auxílio por parte do pesquisador e, com isso, pode gerar um erro intencional de quem está respondendo, invalidando uma das pesquisas.

Buscou-se fazer uma etapa de pré-teste do questionário, a fim de identificar possíveis falhas, como uma inconsistência ou complexidade das questões, ambiguidades ou linguagem inacessível, questões que obedeçam a uma determinada ordem, entre outros. Esta etapa foi realizada com 10 indivíduos que eram do público alvo da pesquisa, no qual, os problemas identificados, foram corrigidos a fim de não atrapalhar a coleta de dados que pudesse causar algum tipo de limitação na análise dos resultados do estudo. 


\section{Apresentação e análise dos resultados}

O presente capítulo busca fazer uma relação dos dados coletados com o principal tema abordado na pesquisa e, a partir desta análise, levantar os números sobre a educação financeira dos participantes. Além de estabelecer relações com o que foi abordado no referencial teórico. Esta análise foi feita baseada nos dados obtidos através da pesquisa quantitativa que foi aplicada.

\subsection{Etapa única: Aplicação do Questionário}

Com os resultados obtidos, será feita uma divisão desta análise em três etapas, sendo elas: a descrição do perfil dos respondentes, os resultados apresentados do público alvo e será feita também uma análise da relevância do problema para o estudo.

\subsubsection{Descrição do perfil dos respondentes}

O primeiro ponto a ser analisado neste tópico é referente a idade, tendo a maior parte dos entrevistados entre 19 e 23 anos, com 131 pessoas, sendo considerada a idade que está o público alvo da pesquisa, equivalente a $59,01 \%$ do total. Além disso, a outra maioria do público respondente, com 22,07\% está entre 24 e 28 anos, influenciando no número de pessoas já com o ensino superior completo que responderam ao questionário. Já em relação ao gênero, dos 222 respondentes, 147 (66,22\%) são homens e 75 (33,78\%) são mulheres.

Quanto a renda dos participantes, foi avaliado todas as formas de receita do indivíduo, como trabalho, mesada, doações, entre outros. Este foi um ponto que variou muito, com 22,97\% alegando que recebem de 1 a 2 salários mínimos, 23,42\% recebem de 2 a 3, 15,32\% recebem de 3 a 4, 9,01\% recebem de 4 a 6, 23,42\% recebem 6 ou mais salários mínimos e o restante $(5,86 \%)$ optou por não responder. Outro fator considerado foi a localização geográfica dos participantes, no qual houve um predomínio de pessoas que moram na Zona Sul do Rio de Janeiro, contando com 158 dos 222 respondentes, o que equivale a 71,17\%, além disso, outras pessoas que não são da cidade do Rio também responderam, que são 9,46\% da amostra. Para finalizar as perguntas gerais da pesquisa, foi questionado se a pessoa já havia se formado, se já estava na graduação ou se possuía apenas o ensino médio completo. Em 
resumo, pode-se observar no quadro abaixo a proporção para as perguntas gerais desta pesquisa:

Quadro 1 - Perfil dos respondentes

\begin{tabular}{|l|r|l|r|}
\hline \multicolumn{2}{|c|}{ Sexo: } & \multicolumn{2}{c|}{ Renda mensal: } \\
\hline Masculino & $66,37 \%$ & $\mathrm{R} \$ 998,00-\mathrm{R} \$ 1.996,00$ (1 a 2 salários mínimos) & $23,01 \%$ \\
\hline Feminino & $33,63 \%$ & $\mathrm{R} \$ 1.996,00-\mathrm{R} \$ 2.994,00$ (2 a 3 salários mínimos) & $23,45 \%$ \\
\hline \multicolumn{1}{|c|}{ Faixa etária: } & $\mathrm{R} \$ 2.994,00-\mathrm{R} \$ 3.992,00$ (3 a 4 salários mínimos) & $15,04 \%$ \\
\hline Menor de 18 anos & $5,75 \%$ & $\mathrm{R} \$ 3.992,00-\mathrm{R} \$ 5.998,00$ (4 a 6 salários mínimos) & $\mathbf{8 , 8 5 \%}$ \\
\hline $19-23$ anos & $59,29 \%$ & $\mathrm{R} \$ 5.998,00 \neq(6$ salários mínimos ou mais) & $23,89 \%$ \\
\hline $24-28$ anos & $22,12 \%$ & Não gostaria de responder & $5,75 \%$ \\
\hline $29-35$ anos & $2,21 \%$ & \multicolumn{1}{|c|}{ Local em que reside: } \\
\hline 36 anos ou mais & $10,62 \%$ & Zona Sul & $71,24 \%$ \\
\hline \multicolumn{1}{|c|}{ Escolaridade: } & Zona Norte & $12,31 \%$ \\
\hline Apenas ensino médio completo & $3,54 \%$ & Zona Oeste & $1,33 \%$ \\
\hline Ensino superior incompleto & $62,83 \%$ & Zona Central & $9,29 \%$ \\
\hline Ensino superior completo & $33,63 \%$ & Não moro no Rio de Janeiro & \\
\hline \hline
\end{tabular}

Fonte: Elaborado pelo autor, a partir da pesquisa de campo, 2019

Como visto no quadro 1, obteve-se um número considerado de pessoas já formadas, o que aumentou o índice de respostas em relação a uma renda mensal consideravelmente alta. Com o intuito de conseguir separar os grupos entre quem teve ou não uma educação financeira formal na escola, pediu-se uma resposta direta entre sim ou não aos respondentes. Como é abordado no trabalho, os dados a seguir comprovam a pergunta principal da pesquisa que, hoje em dia, as escolas não preparam bem os alunos a respeito de ter uma educação financeira formal, pois 195 dos respondentes (90,7\%) afirmam não ter tido este tipo ensino na escola. Já dos 20 respondentes que sobraram $(9,30 \%)$, alegam que tiveram esta educação passada na escola, sendo 8 deles através de aula formal, 3 através de um conteúdo passado de forma paralela e 4 deles afirmam que o contato foi feito por atividades extras, como palestras.

\subsubsection{Descrição e análise dos resultados do público alvo}

Parte do intuito da pesquisa era saber a opinião dos respondentes a respeito do tema. Com isso, foi questionado o grau de importância que os entrevistados atribuíram para aulas de educação financeira nas escolas e, 41,01\% classificou como indispensável, 35,39\% como muito importante, $21,91 \%$ como importante apenas e menos de $2 \%$ responderam que é pouco importante ou não é necessário, como pode-se observar no gráfico 4 a seguir: 


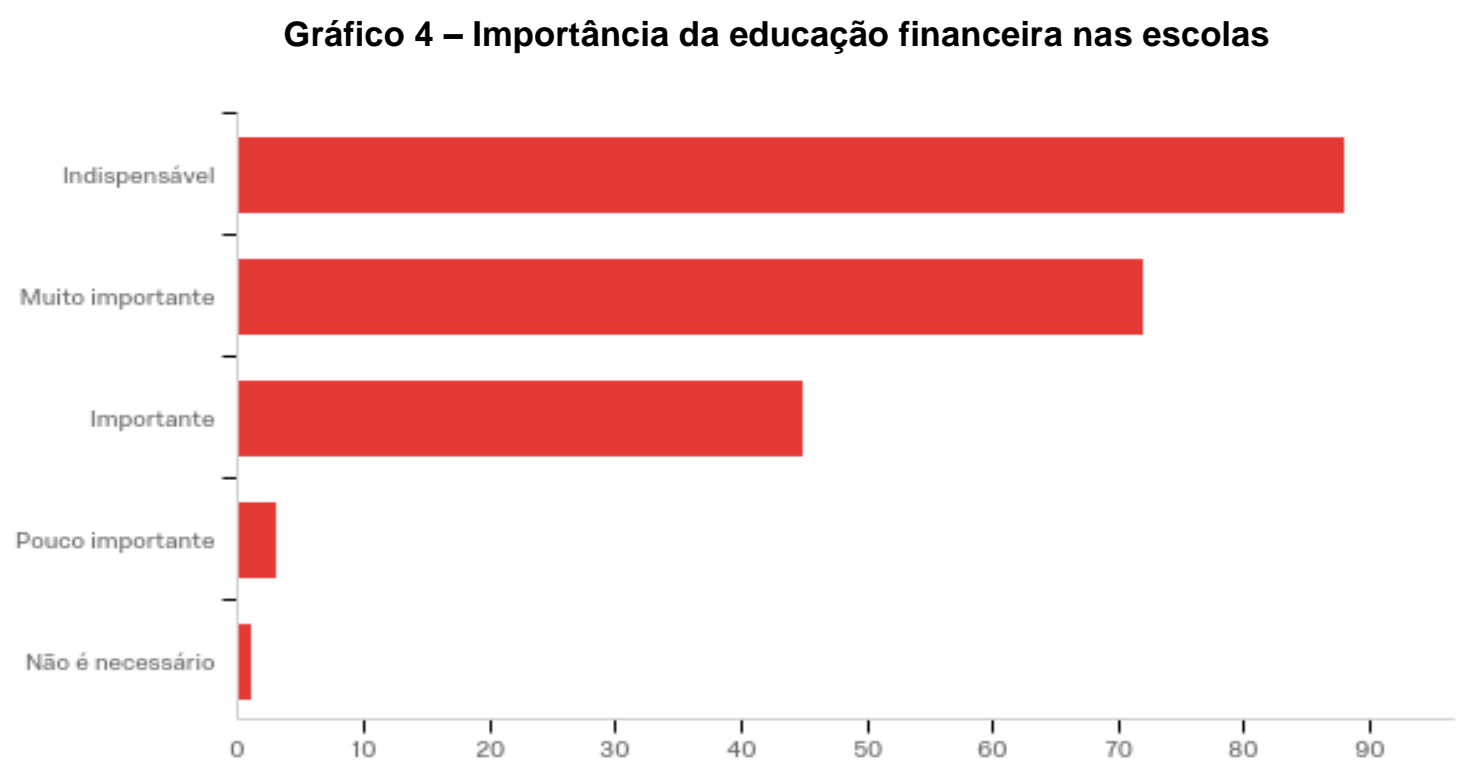

Fonte: Elaborado pelo autor, a partir da pesquisa de campo, 2019

Estabelecendo uma ligação entre as perguntas, também foi questionado se o contato com este ensino desde cedo, viria a influenciar o indivíduo a controlar melhor as suas finanças hoje em dia. Para confirmar a hipótese, 58,99\% dos respondentes concordaram totalmente, $34,83 \%$ concordaram parcialmente, enquanto $5,06 \%$ discordam parcialmente e apenas $1,12 \%$ discordam totalmente. A pesquisa também buscava saber qual era o meio em que foi feito o primeiro contato com esta educação, com a maior parte respondendo que foi feito através da própria família (64,04\%), o segundo maior foi através da faculdade, com 16,29\%, pelos amigos era de $7,87 \%$, pelo trabalho representava $4,49 \%$, e, o que a pesquisa evidenciou é que onde deveria ter sido feito o primeiro contato, na escola, obteve apenas $2,25 \%$ do total.

A fim de conhecer mais o comportamento do público estudado, a maioria das pessoas respondeu que tem hábitos de poupar e controlar seus gastos, o que traduz uma gestão financeira pessoal, com 38,20\% afirmando que sim, praticam totalmente esta gestão, 54,49\% praticam um pouco e apenas $7,30 \%$ não a praticam. A partir deste questionamento, o número de pessoas que conhece os produtos financeiros foi parecido com o de pessoas que praticam a gestão financeira pessoal, pois $40,45 \%$ do público se sentem seguros ao saber a diferença entre os produtos como ações, fundos de investimento e renda fixa, enquanto 47,19\% têm pouco conhecimento sobre os produtos e acreditam que saibam a diferença e apenas $12,36 \%$ não sabem diferenciar tais produtos. 


\subsubsection{Análise do público presente no mercado financeiro}

O tópico presente tem o intuito de levantar dados sobre o público estudado que já faz parte do mercado de investimentos financeiros. Com isso, se tornou essencial o questionamento sobre qual produto financeiro o respondente já investia e, com a possibilidade de ser uma resposta de múltipla escolha, a pessoa poderia optar por mais de um produto financeiro, totalizando 320 escolhas. Assim, como o produto mais investido, foi a renda fixa, com 76 pessoas, equivalente a $23,75 \%$, o segundo produto, foi a poupança com $22,81 \%$, os fundos de investimento ficaram em terceiro, com $21,56 \%$, ações com $14,37 \%$ e outros como bitcoin, fundo imobiliário, COE, PGBL ficaram com apenas 4 votos. Para evidenciar o problema da pesquisa, 52 pessoas responderam que não investem, totalizando $16,25 \%$ do total, o que é maior que o número de pessoas que estão familiarizados com o mercado de renda variável, como pode ser observado no gráfico 5 a seguir:

\section{Gráfico 5 - Investimentos financeiros dos respondentes}

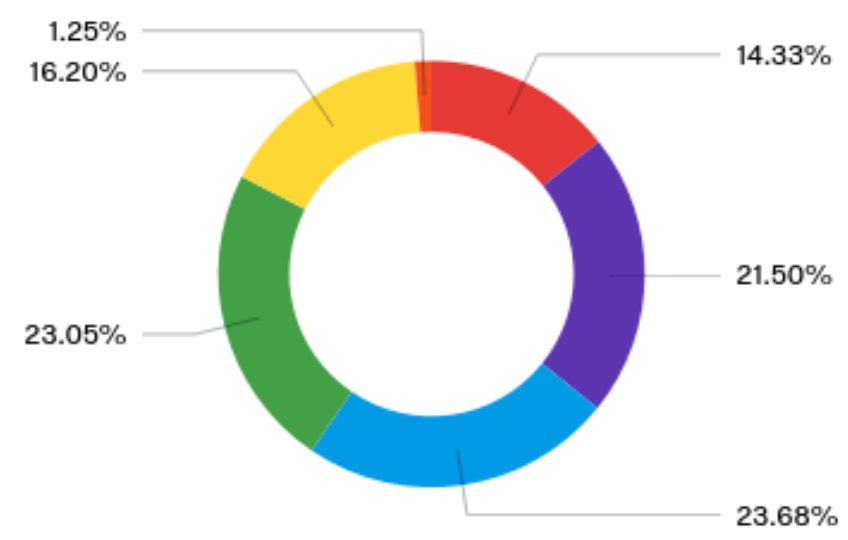

Renda Variável (Açōes). Tundos de Investimento. 
A primeira relação foi feita a fim de conhecer o público que ainda não investe, buscando entender os motivos que levam a pessoa a não investir, com isso, observam-se os dados no gráfico 6:

\section{Gráfico 6 - Por que você não investe hoje?}

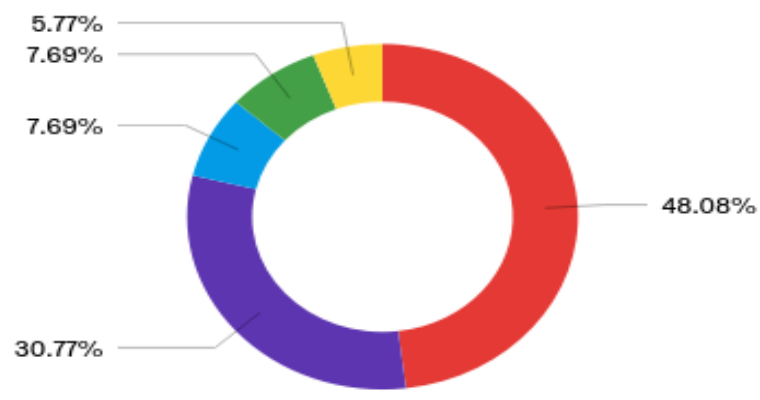

Nāo tenho conhecimento suficiente para isso.

Nāo consigo separar dinheiro suficiente para investimentos financeiros.

Fonte: Elaborado pelo autor, a partir da pesquisa de campo, 2019.

O resultado obtido nesta pergunta está coerente com o que é abordado no trabalho, sendo uma falta de divulgação da educação financeira, na qual as pessoas afirmam não ter este conhecimento, que é algo que deveria ser dado desde cedo para o indivíduo.

Visto que a maioria dos respondentes se classificou como conservador e moderado, com respectivamente $39,74 \%$ e $42,38 \%$, pode-se estabelecer a conexão com a escolha dos produtos na pergunta anterior. Ou seja, a maioria dos respondentes está investindo em produtos financeiros que são classificados como produtos de menor risco, a poupança e renda fixa de baixíssimo risco e, de baixo risco, como no caso dos fundos de investimento. Com $17,88 \%$ que se consideram arrojados, pode ser feita a relação daqueles que investem no mercado de ações. Além disso, este número é resultado da baixa quantidade de pessoas que têm sólido conhecimento do mercado financeiro, característica que é comum na classificação do perfil arrojado.

Por fim, buscou-se saber qual canal era utilizado para fazer o investimento de cada um dos respondentes e, assim, foi originado um número praticamente igual pois $35,96 \%$ fazem seus investimentos por corretoras/distribuidoras de títulos e valores mobiliários e 35,47\% fazem seus investimentos pelo banco em que são clientes. Já $26,11 \%$ do público alegou não 
ter nenhum tipo de investimento, nem pelo próprio banco. As pessoas que investem em produtos além da poupança já possuem contas em corretoras e, por isso, uma relação entre estes dados. Além disso, o número de pessoas que fazem seus investimentos por corretoras tende a crescer, haja vista que por estes lugares há uma maior variedade de produtos financeiros de investimento, maior praticidade para se investir e maior auxílio por parte dos atendentes. Assim, quando feita a comparação pelo Qualtrics, quando o indivíduo selecionou a poupança como seu investimento, pode-se fazer uma relação de que eles ainda investem por bancos, dado que mais de 70 pessoas, 50 escolheram tais respostas juntas. 


\section{Conclusões}

O intuito do estudo foi fazer uma análise da importância e do impacto quando se tem o contato desde cedo com a educação financeira, analisando o caso de pessoas que já passaram pela escola e que hoje estão ainda na faculdade ou já são formados. Além disso, buscou-se trazer à tona os tipos de perfil dos investidores e qual os produtos financeiros que são recomendados para cada um deles.

Um dos primeiros pontos a se destacar é em relação a opinião das pessoas que responderam ao questionário, pois $41,01 \%$ classificou como indispensável a presença de aulas sobre educação financeira no ensino fundamental e médio, 35,39\% como muito importante, $21,91 \%$ como importante apenas e menos de $2 \%$ responderam que é pouco importante ou não é necessário.

Quanto a outros dados levantados através da pesquisa, pode-se afirmar que é de assimilação entre pesquisador e pesquisados a importância da educação financeira desde cedo, sendo introduzida nas escolas e com aulas também nas faculdades. Através da pesquisa, foi visto que há uma presença do público no mercado financeiro de investimento, porém, com as iniciativas e ensinamentos sobre educação financeira, este número pode e deve aumentar. Para ratificar a situação atual, houve uma diferença preponderante entre quem acredita que obteve sim uma educação financeira formal na escola ou não, pois $90,7 \%$ dos respondentes acreditam não ter tido esta educação.

Um dos pontos destacados nas respostas do questionário foi que, dos que não investem, aproximadamente $50 \%$ não o fazem devido a uma falta de conhecimento suficiente para isso. Com isso, percebe-se que o quanto antes o indivíduo começar a entender sobre finanças pessoais, mais ele conseguirá poupar e destinar este dinheiro a investimentos. Uma vez que o jovem já entende desde cedo como faz essa separação do seu dinheiro, ele consegue compreender melhor qual o tipo de investimento que é preferível para ele, sabendo classificar a sua relação entre risco e retorno e, assim, resultando no descobrimento de qual é o seu perfil de investidor.

Ao analisar o trabalho como um todo, percebe-se que a educação financeira é vital na vida de qualquer pessoa que almeja garantir um futuro econômico estável para a sua família. Como já mencionado anteriormente, o que acontece é que há uma falta de divulgação da educação financeira, pois o trabalho também revelou que o acesso a esta informação pode ser feito de forma independente e individual, porém, este processo exige que as pessoas 
estejam comprometidas a buscar esta mudança, que acarretará em uma melhora contínua na vida delas.

Conforme já mencionado no trabalho, já é possível observar algumas ações e atitudes para melhorar o índice de educação financeira no Brasil. Porém, como é de mútuo entendimento entre pesquisador e pesquisados, acredita-se que as escolas, públicas e particulares, poderiam ter mais iniciativas em relação a introdução de aulas práticas e teóricas sobre gestão financeira pessoal. É importante a inclusão de aulas sobre educação financeira direcionadas para cada idade, com atividades sugeridas que são similares ao dia a dia da criança e como ensiná-la a poupar. Hoje em dia, não são lecionadas matérias sobre finanças para todos os cursos, com isso, conclui-se que o ensino sobre educação financeira é algo que deve começar nas escolas e ter continuidade nas faculdades, independente do curso que o aluno está.

A segunda sugestão é direcionada para o público alvo da pesquisa, o público universitário. O que pode se destacar é que muitos ainda consideram a poupança como um investimento positivo, porém, como citado no trabalho, há outras opções de investimentos que são mais rentáveis e tão seguros quanto. Outro ponto que deve aumentar é a migração de clientes de bancos para corretoras pelo fato delas oferecerem uma gama maior de produtos financeiros, com maiores opções de investimento e com taxas menores. Vale ainda destacar que para a maioria do público estudado, o primeiro contato sobre como gerir o seu dinheiro veio da família e, como na minha opinião isso deveria ser um complemento de escola mais família, não possuem um conhecimento pleno do assunto.

Como uma das possíveis recomendações para novos estudos, é aconselhado o acompanhamento das atitudes e ações que estão sendo tomadas pela ENEF. Por fim, é importante passar a ideia de que a pessoa pode deixar de gastar em algo num determinado momento para conseguir economizar o seu dinheiro e direcioná-lo para investimentos, garantindo um futuro economicamente estável para ela e sua família. 


\section{Referências Bibliográficas}

AEF-BRASIL. Modelo Conceitual e Objetivos. 2017. Disponível em:

<http://www.vidaedinheiro.gov.br/modelo-conceitual-e-objetivos/>. Acesso em: 15 abr. 2019.

AEF-BRASIL. Relatório Anual 2016. 2016. Disponível em:

<http://www.vidaedinheiro.gov.br/wp-content/uploads/2017/04/Relat\%C3\%B3rio-Anual2016.pdf>. Acesso em: 02 jun. 2019.

ANDRADA, Alexandre. Uma Breve História da Economia Brasileira (1948-2018). The Huffington Post Brasil. Brasília, 07 abr. 2016. Disponível em:

$<$ https://www.huffpostbrasil.com/alexandre-andrada/uma-breve-historia-da-economiabrasileira-1948-2018_a_21686394/>. Acesso em: 10 mar. 2019.

\section{ASSOCIAÇÃO BRASILEIRA DAS ENTIDADES DOS MERCADOS FINANCEIROS DE} CAPITAIS - ANBIMA. Classificação dos Investidores e Suitability no Mercado de Valores Mobiliários. 2014. Disponível em:

<http://www.anbima.com.br/pt_br/informar/regulacao/informe-de-legislacao/classificacaodos-investidores-e-suitability-no-mercado-de-valores-mobiliarios.htm>. Acesso em: 26 mar. 2019.

BANCO CENTRAL DO BRASIL. Pronunciamento do Presidente Ilan Goldfajn: Discurso de abertura da 5ª Semana de Educação Financeira 2018. 2018. Disponível em:

$<$ https://www.bcb.gov.br/conteudo/home-

ptbr/TextosApresentacoes/Discurso_Presidente_Ilan_VSem_Educ_Financeira18_vpub.pdf >. Acesso em: 30 mar. 2019.

BANCO DO BRASIL. Análise de Perfil do Investidor: Entenda os perfis. 2014. Disponível em: <https://www.bb.com.br/portalbb/hs001003,500900,500901,6,0,1,1,80.bb?>. Acesso em: 23 abr. 2019.

BONA, André. A Confiança do Investidor nas Decisões de Investimento. 2018. Blog BTG Pactual digital. Disponível em: <https://www.btgpactualdigital.com/blog/coluna-andrebona/a-confianca-do-investidor-nas-decisoes-de-investimento>. Acesso em: 02 abr. 2019. 
BONA, André. Perfil do Investidor: o que é e como funciona?. 2017. Blog Renda Fixa. Disponível em: <http://www.blog.rendafixa.rocks/investimentos/perfil-do-investidor-o-que-ee-como-funciona/>. Acesso em: 22 mar. 2019.

BRASIL. Instrução Normativa 539 da Comissão de Valores Mobiliários, de 13 de novembro de 2013. Dispõe sobre o dever de verificação da adequação dos produtos, serviços e operações ao perfil do cliente. Diário Oficial da República Federativa do Brasil, Brasília, DF, 13 nov. 2013. Disponível em:<http://www.cvm.gov.br/export/sites/cvm/legislacao/instrucoes/anexos/500/inst539consoli d.pdf>. Acesso em: 10 abr. 2019.

BRUHN, M. et al.The impact of high school financial education: experimental evidence from Brazil. Washington, DC: Development Research Group \& Latin America and Caribbean Region / The World Bank, 2013. 55 p. (Policy Research Working Paper, n. 6723).Disponível em:

<http://wwwwds.worldbank.org/external/default/WDSContentServer/WDSP/IB/2013/12/12/00 0158349_20131212094211/Rendered/PDF/WPS6723.pdf>. Acesso em: 13 set. 2019.

\section{CAIXA ECONÔMICA FEDERAL - CEF. Perguntas Frequentes sobre Fundos de} Investimento: Qual Fundo de Investimento é mais indicado para mim?. 2014. Disponível em: <http://www.caixa.gov.br/fundos-investimento/perguntasfrequentes/Paginas/default.aspx>. Acesso em: 15 maio 2019.

CAMOZZATO, Elen Sauer; LIZOTE, Suzete Antonieta; VERDINELLI, Miguel Angel. Educação Financeira e Intenção Empreendedora: Um Estudo com Alunos de Administração. In: CONGRESSO LATINO-AMERICANO E ADMINISTRAÇÃO DE NEGÓCIOS - CONLAAN, 07-09 jun. 2017, Ponta Grossa, Paraná. Disponível em: <https://www.conlaan.com.br/2017/artigo_nome/250_05052017_81.pdf>. Acesso em: 20 fev. 2019.

CALEGARI, Luiza. Brasileiro prefere investir em poupança, e acha que Bolsa é 'para ricos': Por que o brasileiro não investe em ações?. 2012. Economia UOL. Disponível em: <https://economia.uol.com.br/noticias/redacao/2012/12/14/brasileiro-prefere-investir-empoupanca-e-acha-que-bolsa-e-para-ricos.htm>. Acesso em: 25 out. 2018. 


\section{COMISSÃO DE VALORES MOBILIÁRIOS - CVM. 6a Semana Nacional de Educação}

Financeira. 2019. Disponível em: <http://www.cvm.gov.br/noticias/arquivos/2019/201905032.html>. Acesso em: 20 maio 2019.

D'ANDRÉA, Gabriela. Invista como Einstein, sugere especialista. 2013. Infomoney: em Onde-Investir/Renda-Fixa. Disponível em: <https://www.infomoney.com.br/ondeinvestir/renda-fixa/noticia/2622248/invista-como-einstein-sugere-especialista>. Acesso em: 30 mar. 2019.

D'ÁVILA, Mariana. Fundos, ações ou renda fixa: onde os milionários estão investindo: Cada um no seu quadrado. Elaborado por: Infomoney. Disponível em: <https://www.infomoney.com.br/onde-investir/renda-fixa/noticia/7909972/fundos-acoes-ourenda-fixa-onde-os-milionarios-estao-investindo>. Acesso em: 20 maio 2019.

DICIONÁRIO FINANCEIRO. O que é risco nos investimentos? 2017. Disponível em: <https://www.dicionariofinanceiro.com/risco-nos-investimentos/>. Acesso em: 10 maio 2019.

DINO. Especialista Explica a Importância de Começar a Investir Cedo. Exame. São Paulo, 03 abr. 2017. Disponível em: <https://exame.abril.com.br/negocios/dino/especialista-explicaa-importancia-de-comecar-a-investir-cedo-shtml/>. Acesso em: 10 abr. 2019.

DODD, Nigel. A Sociologia do dinheiro. Rio de Janeiro: Fgv - Fundação Getúlio Vargas, 1997.

DOMINGUES, Reinaldo. Terapia Financeira. Brasil: Dsop, 2008. Disponível em: $<$ https://kupdf.net/download/terapia-financeira-reinaldo-domingospdf_59f5628fe2b6f5f244ebfc46_pdf>. Acesso em: 12 out. 2018.

DONADIO, Rosimara; SILVEIRA, Amélia; SOUZA, Almir Ferreira de. Educação financeira de estudantes universitários: uma análise dos fatores de influência. 2016. Disponível em: <https://bibliotecadigital.fgv.br/dspace/bitstream/handle/10438/18897/GVcef_Donadio\%3B\% 20Sousa\%3B\%20Silveira. pdf? sequence=1\&isAllowed=y>. Acesso em: 05 abr. 2019. 
EKER, T. Harv. Os segredos da mente milionária. Rio de Janeiro: Sextante, 2005. Tradução de: Pedro Jorgensen Junior. Disponível em: <https://negociosinvest.com/wpcontent/uploads/2018/06/Os-Segredos-da-Mente-Milionaria-T.-Harv-Eker.pdf>. Acesso em: 31 mar. 2019.

\section{ESTRATÉGIA NACIONAL DE EDUCAÇÃO FINANCEIRA - ENEF. Plano Diretor ENEF.} [2008]. Disponível em: <http://www.vidaedinheiro.gov.br/wp-content/uploads/2017/08/PlanoDiretor-ENEF-Estrategia-Nacional-de-Educacao-Financeira.pdf>. Acesso em: 10 maio 2019.

GENIAL INVESTIMENTOS. O que torna um investimento conservador, moderado ou arrojado: Investimentos moderados. 2017. Disponível em:

$<$ https://blog.genialinvestimentos.com.br/o-que-torna-um-investimento-conservadormoderado-ou-arrojado/>. Acesso em: 20 maio 2019.

GRAHAM, Benjamin. O Investidor Inteligente. [S. I.]: Harper Collins, 1949. Disponível em: <http://ysdronnewstime.weebly.com/uploads/5/9/8/2/59820101/o_investidor_inteligente__benjamin_grahamm.pdf>. Acesso em: 20 abr. 2019.

HAIR, Joseph Fielding et al. Análise Multivariada de Dados. 6. ed. S. L: Bookman, 2005.

INFOMONEY. Fundos DI e de renda fixa: entenda as principais diferenças entre as classes: Fundos referenciados DI. 2005. Disponível em:

$<$ https://www.infomoney.com.br/mercados/noticia/429676/fundos-di-e-de-renda-fixa-entendaas-principais-diferencas-entre-as-classes>. Acesso em: 02 jun. 2019.

INSTITUTO AYRTON SENNA. BNCC: construindo um currículo de educação integral: O que é a BNCC. 2018. Disponível em: <https://institutoayrtonsenna.org.br/pt-br/BNCC/o-quee-BNCC.html>. Acesso em: 05 out. 2018.

ITAÚ. Investimento CDB e Renda Fixa : O que é CDB e Renda Fixa?. [201-]. Disponível em: <https://www.itau.com.br/investimentos-previdencia/cdb-renda-fixa/>. Acesso em: 30 maio 2019.

KIYOSAKI, Robert; LECHTER, Sharon L.. Pai Rico, Pai Pobre. Estados Unidos: Campus, 1997. Disponível em: < 
https://drive.google.com/file/d/1MMIsoSCyqG_16bKx4S1efP6xBRt7jBtf/view>. Acesso em: 05 abr. 2019.

LARGHI, Nathália. Jovens ampliam participação na bolsa. Valor Econômico. São Paulo, 24 jan. 2018. Disponível em: <https://www.valor.com.br/financas/5277877/jovens-ampliamparticipacao-na-bolsa>. Acesso em: 10 nov. 2018.

MARQUES, Wallace de Anchieta. Semelhanças e Diferenças entre Instituições que Oferecem Educação Financeira no Brasil. 2018. 92 f. TCC (Graduação) - Curso de Economia, Instituto de Economia, Universidade Federal do Rio de Janeiro, Rio de Janeiro, 2018. Cap. 2. Disponível em: <http://www.vidaedinheiro.gov.br/wpcontent/uploads/2018/11/201801_Monografia_Wallace-de-Anchieta-Marques_rev.pdf>. Acesso em: 30 mar. 2019.

MATTAR, F. N. Pesquisa de marketing. 3.ed. São Paulo: Atlas, 2001.

MINISTÉRIO DA EDUCAÇÃO - MEC. Ensino de educação financeira é importante para desenvolvimento de crianças e adolescentes. 2017. Disponível em:

<http://portal.mec.gov.br/ultimas-noticias/211-218175739/58211-ensino-de-educacaofinanceira-e-importante-para-desenvolvimento-de-criancas-e-adolescentes>. Acesso em: 02 mar. 2019.

PITOL, Tabata. As dicas de Robert Kiyosaki para você viver de renda extra. 2013. Infomoney: em Onde-Investir. Disponível em: <https://www.infomoney.com.br/ondeinvestir/noticia/2668385/dicas-robert-kiyosaki-para-voce-viver-renda>. Acesso em: 20 jan. 2019.

PRODANOV, Cleber Cristiano; FREITAS, Ernani Cesar de. Metodologia do Trabalho Cientifico: Métodos e Técnicas da Pesquisa e do Trabalho Acadêmico. 2. ed. Novo Hamburgo: Universidade Feevale, 2013. Disponível em: <http://www.feevale.br/Comum/midias/8807f05a-14d0-4d5b-b1ad-1538f3aef538/Ebook\%20Metodologia\%20do\%20Trabalho\%20Cientifico.pdf>. Acesso em: 05 abr. 2019. 
SANTANDER. COE (Certificado de Operações Estruturadas). 2019. Disponível em: <https://www.santander.com.br/investimentos-e-previdencia/certificado-de-operacoesestruturadas>. Acesso em: 01 jun. 2019.

SANTANDER. Fundos de Investimento: Categorias de Fundos de Investimento. 2019. Disponível em: <https://www.santander.com.br/investimentos-e-previdencia/fundos-deinvestimento>. Acesso em: 01 jun. 2019.

SANTANDER. Fundos Imobiliários. 2019. Disponível em:

<https://www.santander.com.br/investimentos-e-previdencia/fundos-imobiliarios>. Acesso em: 01 maio 2019.

SANTANDER. Perfil arrojado. 2019. Disponível em:

<https://www.santander.com.br/investimentos-e-previdencia/carteira-perfil-arrojado>. Acesso em: 30 mai. 2019.

SANTANDER. Perfil moderado. 2019. Disponível em:

<https://www.santander.com.br/investimentos-e-previdencia/carteira-perfil-moderado>. Acesso em: 30 maio 2019.

SAVÓIA, J.R. et al. Paradigmas da educação financeira no Brasil, RAP, v.41, n.6, p.1121-41, Rio de Janeiro, Nov./Dez.

2007

SILVA, José. Você não Investe na Bolsa de Valores? Por quê? 2017. Disponível em: <https://www.clubedopairico.com.br/voce-investe-na-bolsa-de-valores-por-que/32532>. Acesso em: 14 mar. 2019.

STANLEY, Thomas J.; DANKO, William D.. O milionário mora ao lado. [S. I.]: Manole, 1996. Disponível em: <http://shoppingdiaenoitecriarsite.weebly.com/uploads/1/0/5/3/10536262/omilionariomoraaolado.pdf>. Acesso em: 05 abr. 2019.

SUPERINTENDÊNCIA NACIONAL DE PREVIDÊNCIA COMPLEMENTAR - PREVIC. O que é Educação Financeira?. [200-?]. Disponível em: 
<http://www.previc.gov.br/regulacao/educacao-previdenciaria/educacao-financeira-eprevidenciaria/o-que-e-educacao-financeira>. Acesso em: 13 abr. 2019

TORO INVESTIMENTOS. O que é BM\&F? - Bolsa de Mercadorias \& Futuros: O que é BM\&F?. 2019. Disponível em: <https://blog.toroinvestimentos.com.br/bmf-o-que-e-bolsa-demercadorias-futuros>. Acesso em: 01 jun. 2019.

UOL EDUCAÇÃO. Plano Real - Fim da inflação e conquista da estabilidade econômica. 2014. Disponível em: <https://educacao.uol.com.br/disciplinas/historia-brasil/plano-real-fimda-inflacao-e-conquista-da-estabilidade-economica.htm>. Acesso em: 20 abr. 2019. 


\section{Documentos Anexos}

\section{Educação Financeira nas Escolas}

\section{Início do bloqueio: Perguntas gerais}

O presente questionário tem como objetivo coletar informações sobre a educação financeira de cada participante.

Gostaria de contar com a sua colaboração, respondendo algumas perguntas que levarão somente alguns minutos. Vale lembrar que não existe resposta certa ou errada, este questionário é feito apenas com o intuito de levantar dados para uma pesquisa.

Desde já agradeço pela sua contribuição!

Qual a sua idade?
18 ou menos (1)
$19-23(2)$
$24-28$
$29-35(4)$
36 ou mais (5)

Sexo:

Feminino (1)

Masculino (2) 
Qual a sua renda mensal (favor considerar todo o dinheiro que é destinado a você, podendo ser mesada, salário, entre outros)? Caso não esteja trabalhando no momento, considere o momento em que já esteve para o somatório, se houver.

$\mathrm{R} \$ 998,00$ - R\$ 1.996,00 (1 a 2 salários mínimos) (1)

$R \$ 1.996,00-R \$ 2.994,00$ (2 a 3 salários mínimos) (2)

$R \$ 2.994,00$ - R\$ 3.992,00 (3 a 4 salários mínimos) (3)

$\mathrm{R} \$$ 3.992,00 - $\mathrm{R} \$ 5.998,00$ (4 a 6 salários mínimos) (4)

$R \$ 5.998,00$ + (6 salários mínimos ou mais) (5)

Não gostaria de responder (6)

Você mora no Rio de Janeiro? Se sim, onde?

Zona Sul (1)

Zona Norte (2)

Zona Oeste (3)

Zona Central (4)

Não moro no Rio de Janeiro (5)

Você está na faculdade hoje em dia ou já é graduado?

Sim, estou na faculdade. (1)

Já sou formado. (2)

Ainda não comecei a graduação. (3) 
Início do bloqueio: Perguntas sobre educação financeira

As perguntas a seguir serão sobre o tema de educação financeira.

Você considera que a sua escola ofereceu uma educação financeira formal? Leve em conta os ensinamentos sobre manejar as suas finanças, como poupar dinheiro, separar e não desperdiçar.

Sim. (1)

Não. (2)

Exibir esta pergunta:

If Você considera que a sua escola ofereceu uma educação financeira formal? Leve em conta os ensinam... = Sim.

Como este contato foi feito?

Aula formal. (1)

Estudo de outras disciplinas e o conteúdo foi passado de forma paralela. (2)

Atividades extras (palestras). (3)

Outro: (4) 
Que grau de importância você atribui para aulas de Educação Financeira no ensino fundamental e médio?
Indispensável (1)
Muito importante (2)
Importante (3)
Pouco importante (4)
Não é necessário (5)

Você acredita que se tivesse tido o contato desde cedo com a Educação Financeira, hoje saberia controlar melhor as suas finanças?

Sim, concordo totalmente. (1)

Sim, concordo parcialmente. (2)

Não, discordo parcialmente. (3)

Não, discordo totalmente. (4) 
Como foi feito o seu primeiro contato com assuntos relacionados a finanças pessoais?

Escola (1)

Família (2)

Faculdade (3)

Amigos (4)

Trabalho (5)

Não tive (6)

Outro: (7)

Você pratica uma gestão financeira pessoal? Ou seja, você possui hábitos de poupar, controlar seus gastos e acredita que não desperdice seu dinheiro?

Sim, totalmente. (1)

Sim, um pouco. (2)

Não. (3)

Hoje, temos produtos financeiros como, ações, fundos de investimento e renda fixa, você sabe diferenciá-los?

Me sinto seguro ao dizer que sei a diferença entre eles. (1)

Tenho pouco conhecimento sobre os produtos, mas acredito que sei a diferença. (2)

Não sei a diferença entre estes produtos. (3) 
Hoje em dia você investe em algum produto financeiro? Qual? Marque mais de uma opção se for o caso.

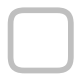

Renda Variável (Ações). (1)
Fundos de Investimento. (2)

Renda Fixa (CDB, LCI, LCA, LF, Tesouro Direto). (3)

Poupança (4)

Não invisto (5)

Outro: (6)

\section{Exibir esta pergunta:}

If Hoje em dia você investe em algum produto financeiro? Qual? Marque mais de uma opção se for o cas... = Não invisto

Por quê você não investe hoje em dia?

Não tenho conhecimento suficiente para isso. (1)

Não consigo separar dinheiro suficiente para investimentos financeiros. (2)

Não tenho tempo no meu dia a dia para isso. (3)

Tenho medo de ser algo arriscado. (4)

Outro: (5) 
Para você que tem investimentos, você tem qual perfil de investidor?

Conservador (priorizo mais a segurança do que a rentabilidade em meus investimentos). (1)

Moderado (invisto em produtos que buscam maior rentabilidade também, mas a maioria dos meus investimentos está em algo mais seguro). (2)

Arrojado (me preocupo menos com o risco e busco a maior rentabilidade em meus investimentos). (3)

Como é feito o seu investimento financeiro?

Faço através da minha corretora/distribuidora de títulos e valores mobiliários. (1)

O meu investimento é feito pelo banco em que sou cliente. (2)

Não possuo nenhum tipo de investimento, nem pelo meu banco. (3)

Outro: (4) 